\title{
International Journal of Advanced Research in Electrical, Electronics and Instrumentation Engineering
}

(An ISO 3297: 2007 Certified Organization)

Vol. 4, Issue 11, November 2015

\section{Combined Economic Emission Dispatch Solution using Modified Artificial Bee Colony Algorithm}

\author{
Hardiansyah $^{1}$, Rusman $^{2}$ \\ Dept. of Electrical Engineering, University of Tanjungpura, Indonesia ${ }^{1}$ \\ Dept. of Electrical Engineering, State Polytechnic of Pontianak, Indonesia ${ }^{2}$
}

\begin{abstract}
In this paper, a new approach is proposed to solve combined economic emission dispatch (CEED) problem in power systems using modified artificial bee colony (MABC) algorithm considering the power limits. The CEED is to minimize both the operating fuel cost and emission level simultaneously while satisfying the load demand and operational constraints. A novel best mechanism algorithm based on $\mathrm{ABC}$ algorithm, in which a new mutation strategy inspired from the differential evolution (DE) is introduced in order to improve the exploitation process. The effectiveness of the proposed algorithm has been tested on IEEE 30-bus test system and the results were compared with other methods reported in recent literature. The simulation results show that the proposed algorithm outperforms previous optimization methods.
\end{abstract}

KEYWORDS: Economic dispatch, emission dispatch, combined economic emission dispatch, modified artificial bee colony algorithm, differential evolution.

\section{INTRODUCTION}

Economic dispatch (ED) is one of the most fundamental issues in power system operation and control for allocating generation among the committed units. The objective of the ED problem is to determine the amount of real power contributed by online thermal generators satisfying load demand at any time subject to unit and system constraints so as the total generation cost is minimized. Therefore, it is very important to solve the problem as quickly and precisely as possible [1,2]. Therefore, recently most of the researchers made studies for finding the most suitable power values produced by the generators depending on fuel costs. In these studies, they produced successful results by using various optimization algorithms [3-5]. Despite the fact that the traditional ED can optimize generator fuel costs, it still can not produce a solution for environmental pollution due to the excessive emission of fossil fuels.

Currently, a large part of energy production is done with thermal sources. Thermal power plant is one of the most important sources of carbon dioxide $\left(\mathrm{CO}_{2}\right)$, sulfur dioxide $\left(\mathrm{SO}_{2}\right)$ and nitrogen oxides $\left(\mathrm{NO}_{\mathrm{x}}\right)$ which create atmospheric pollution [6]. Emission control has received increasing attention owing to increased concern over environmental pollution caused by fossil based generating units and the enforcement of environmental regulations in recent years [7]. Numerous studies have emphasized the importance of controlling pollution in electrical power systems [8].

Combined economic and emission dispatch (CEED) has been proposed in the field of power generation dispatch, which simultaneously minimizes both fuel cost and pollutant emissions. When the emission is minimized the fuel cost may be unacceptably high or when the fuel cost is minimized the emission may be high. A number of methods have been presented to solve CEED problems such as simplified recursive method [9], genetic algorithm [10-12], simulated annealing [13], biogeography based optimization [14], particle swarm optimization [15, 16], and artificial bee colony algorithm $[17,18]$.

In this paper, we propose a novel best search mechanism to improve original $\mathrm{ABC}$ algorithm. In this way, the newly generated candidate solutions are always around the random solutions of the previous iteration. Moreover, a controlled parameter is introduced to control the frequency of perturbation. By combing these methods, a modified algorithm as 


\title{
International Journal of Advanced Research in Electrical, Electronics and Instrumentation Engineering
}

\author{
(An ISO 3297: 2007 Certified Organization)
}

\section{Vol. 4, Issue 11, November 2015}

called MABC is proposed. Combined economic emission dispatch (CEED) solution which was performed using MABC algorithm was tested over a standard IEEE 30-bus test system which consisted of six generators. The results were compared to those reported in the literature.

\section{PROBLEM FORMULATIONS}

The EED problem targets to find the optimal combination of load dispatch of generating units and minimizes both fuel cost and emission while satisfying the total power demand. Therefore, EED consists of two objective functions, which are economic and emission dispatches. Then these two functions are combined to solve the problem. The EED problem can be formulated as follows [11]:

$$
F_{T}=\operatorname{Min} f(F C, E C)
$$

where $F_{T}$ is the total generation cost of the system, $F C$ is the total fuel cost of generators and $E C$ is the total emission of generators.

\subsection{Economic Dispatch (ED)}

The ED problem targets to find the optimal combination of power generation by minimizing the total fuel cost of all generator units while satisfying the total demand. The ED problem can be formulated in a quadratic form as follows [11]:

$$
F_{C}=\sum_{i=1}^{N}\left(a_{i} P_{i}^{2}+b_{i} P_{i}+c_{i}\right)
$$

where $P_{i}$ is the power generation of the $i$ th unit; $a_{i}, b_{i}$, and $c_{i}$ are fuel cost coefficients of the $i$ th generating unit and $N$ is the number of generating units.

\subsection{Emission Dispatch (ED)}

The classical ED problem can be obtained by the amount of active power to be generated by the generating units at minimum fuel cost, but it is not considered as the amount of emissions released from the burning of fossil fuels. Total amount of emissions such as SO2 or NOx depends on the amount of power generated by until and it can be defined as the sum of a quadratic function as follows [11]:

$$
E C=\sum_{i=1}^{N}\left(\alpha_{i} P_{i}^{2}+\beta_{i} P_{i}+\gamma_{i}\right)
$$

where $\alpha_{i}, \beta_{i}$ and $\gamma_{i}$ are emission coefficients of the $i$ th generating unit.

\subsection{Combined Economic Emission Dispatch (CEED)}

CEED is a multi-objective problem, which is a combination of both economic and environmental dispatches that individually make up different single problems. At this point, this multi-objective problem needs to be converted into single-objective form in order to fulfill optimization. The conversion process can be done by using the price penalty factor. However, the single-objective EED can be formulated as shown in equation (4) [11, 18]:

$$
\operatorname{Min} F_{T}=\sum_{i=1}^{N}\left(\left(a_{i} P_{i}^{2}+b_{i} P_{i}+c_{i}\right)+h_{i}\left(\alpha_{i} P_{i}^{2}+\beta_{i} P_{i}+\gamma_{i}\right)\right)(\$ / h)
$$

where $h_{i}$ is the price penalty factor, and is formulated as follows:

$$
h_{i}=\frac{a_{i} P_{i \max }^{2}+b_{i} P_{i \max }+c_{i}}{\alpha_{i} P_{i \max }^{2}+\beta_{i} P_{i \max }+\gamma_{i}}
$$

where $P_{i \max }$ is the maximum power generation of the $i$ th unit in MW.

\subsection{Problem Constraints}

There are two constraints in the EED problem which are power balance constraint and maximum and minimum limits of power generation output constraint. 


\title{
International Journal of Advanced Research in Electrical, Electronics and Instrumentation Engineering
}

\author{
(An ISO 3297: 2007 Certified Organization)
}

\section{Vol. 4, Issue 11, November 2015}

Power balance constraint:

$$
\begin{aligned}
& \sum_{i=1}^{N} P_{i}=P_{D}+P_{L} \\
& P_{L}=\sum_{i}^{N} \sum_{j}^{N} B_{i j} P_{i} P_{j}
\end{aligned}
$$

Generating capacity constraint:

$$
P_{i \min } \leq P_{i} \leq P_{i \max }
$$

where $P_{D}$ is total demand of the system (MW), and $P_{L}$ is total power loss (MW). $P_{i m i n}, P_{i m a x}$, and $B_{i j}$ are minimum generation of unit $i(\mathrm{MW})$, maximum generation of unit $i(\mathrm{MW})$, and coefficients of transmission losses respectively.

\section{ARTIFICIAL BEE COLONY (ABC) ALGORITHM}

Artificial bee colony is one of the most recently defined algorithms by Karaboga in 2005, motivated by the intelligent behaviour of honey bees $[19,20]$. In the ABC system, artificial bees fly around in the search space, and some (employed and onlooker bees) choose food sources depending on the experience of themselves and their nest mates, and adjust their positions. Some (scouts) fly and choose the food sources randomly without using experience. If the nectar amount of a new source is higher than that of the previous one in their memory, they memorize the new position and forget the previous one [20]. Thus, the ABC system combines local search methods, carried out by employed and onlooker bees, with global search methods, managed by onlookers and scouts, attempting to balance exploration and exploitation process.

In the $\mathrm{ABC}$ algorithm, the colony of artificial bees consists of three groups of bees: employed bees, onlooker bees, and scout bees. The main steps of the ABC algorithm are described as follows:

- Initialize.

- REPEAT.

(a) Place the employed bees on the food sources in the memory;

(b) Place the onlooker bees on the food sources in the memory;

(c) Send the scouts to the search area for discovering new food sources;

(d) Memorize the best food source found so far.

- UNTIL (requirements are met).

In the $\mathrm{ABC}$ algorithm, each cycle of the search consists of three steps: moving the employed and onlooker bees onto the food sources, calculating their nectar amounts respectively, and then determining the scout bees and moving them randomly onto the possible food source. Here, a food source stands for a potential solution of the problem to be optimized. The ABC algorithm is an iterative algorithm, starting by associating all employed bees with randomly generated food solutions. The initial population of solutions is filled with $S N$ number of randomly generated $D$ dimensions. Let $X_{i}=\left\{x_{i 1}, x_{i 2}, \ldots, x_{i D}\right\}$ represent the $i$ th food source in the population, $S N$ is the number of food source equal to the number of the employed bees and onlooker bees. $D$ is the number of optimization parameters. Each employed bee $x_{i j}$ generates a new food source $v_{i j}$ in the neighborhood of its currently associated food source by (9), and computes the nectar amount of this new food source as follows:

$$
v_{i j}=x_{i j}+\varphi_{i j}\left(x_{i j}-x_{k j}\right)
$$

where $\varphi_{i j}=($ rand -0.5$) \times 2$ is a uniformly distributed real random number within the range [-1, 1], $i \in\{1,2, \ldots, S N\}, k=\operatorname{int}(\operatorname{rand} * S N)+1$ and $k \neq i$, and $j \in\{1,2, \ldots, D\}$ are randomly chosen indexes. The new solution $v_{i}$ will be accepted as a new basic solution, if the objective fitness of $v_{i}$ is smaller than the fitness of $x_{i}$, otherwise $x_{i}$ would be obtained.

When all employed bees finish this process, an onlooker bee can obtain the information of the food sources from all employed bees and choose a food source according to the probability value associated with the food source, using the following expression: 


\section{International Journal of Advanced Research in Electrical, Electronics and Instrumentation Engineering}

(An ISO 3297: 2007 Certified Organization)

\section{Vol. 4, Issue 11, November 2015}

$$
p_{i}=\alpha \times \frac{f i t_{i}}{\max \left(f i t_{i}\right)}+\beta ; \quad \alpha+\beta=1
$$

where $f_{i t}$ is the fitness value of the solution $i$ evaluated by its employed bee. Obviously, when the maximum value of the food source decreases, the probability with the preferred source of an onlooker bee decreases proportionally. Then the onlooker bee produces a new source according to (9). The new source will be evaluated and compared with the primary food solution, and it will be accepted if it has a better nectar amount than the primary food solution.

After all onlookers have finished this process, sources are checked to determine whether they are to be abandoned. If the food source does not improve after a determined number of the trails "limit", the food source is abandoned. Its employed bee will become a scout and then will search for a food source randomly as follows:

$$
x_{i j}=x_{j \text { min }}+\operatorname{rand}(0,1) *\left(x_{j \max }-x_{j \text { min }}\right)
$$

where $x_{j \min }$ and $x_{j \max }$ are lower and upper bounds for the dimension $j$ respectively.

After the new source is produced, another iteration of the $\mathrm{ABC}$ algorithm will begin. The whole process repeats again till the termination condition is met.

\section{MODIFIED ARTIFICIAL BEE COLONY (MABC) ALGORITHM}

Following this spirit, a modified ABC algorithm inspired from differential evolution (DE) to optimize the objective function of the ED problems. Differential evolution is an evolutionary algorithm first introduced by Storn and Price $[23,24]$. Similar to other evolutionary algorithms, particularly genetic algorithm, DE uses some evolutionary operators like selection recombination and mutation operators. Different from genetic algorithm, DE uses distance and direction information from the current population to guide the search process. The crucial idea behind DE is a scheme for producing trial vectors according to the manipulation of target vector and difference vector. If the trail vector yields a lower fitness than a predetermined population member, the newly trail vector will be accepted and be compared in the following generation. Currently, there are several variants of DE. The particular variant used throughout this investigation is the DE/rand/1 scheme. The differential mutation strategy is described by the following equation:

$$
v_{i}=x_{a}+F\left(x_{b}-x_{c}\right)
$$

where $a, b, c \in S N$ are randomly chosen and mutually different and also different from the current index $i$. $F \in(0,1)$ is constant called scaling factor which controls amplification of the differential variation of $x_{b j}-x_{c j}$.

Based on DE and the property of ABC algorithm, we modify the search solution described by (13) as follows:

$$
v_{i j}=x_{a j}+\varphi_{i j}\left(x_{i j}-x_{b j}\right)
$$

The new search method can generate the new candidate solutions only around the random solutions of the previous iteration.

Akay and Karaboga [21] proposed a modified artificial bee colony (MABC) algorithm by controlling the frequency of perturbation. Inspired by this algorithm, we also use a control parameter, i.e., modification rate $(M R)$. In order to produce a candidate food position $v_{i j}$ from the current memorized $x_{i j}$, improved ABC algorithm uses the following expression [21, 22]:

$$
v_{i j}= \begin{cases}x_{a j}+\varphi_{i j}\left(x_{i j}-x_{b j}\right), & \text { if } R_{i j} \leq M R \\ x_{i j} & \text { otherwise }\end{cases}
$$

where $R_{i j}$ is a uniformly distributed real random number within the range $[0,1]$. The pseudo-code of the MABC algorithm is given below: 


\title{
International Journal of Advanced Research in Electrical, Electronics and Instrumentation Engineering
}

\author{
(An ISO 3297: 2007 Certified Organization)
}

Vol. 4, Issue 11, November 2015

Initialize the population of solutions $x_{i j}, i=1 \ldots S N ; j=1 \ldots D$, trial $_{i}=0 ;$ trial $_{i}$ is the non-improvement number of the solution $x_{i}$, used for abandonment

Evaluate the population

cycle $=1$

repeat

for $i=1$ to $S N$ do

\{--- Produce a new food source population for employed bee --- $\}$

Produce a new food source $v_{i}$ for the employed bee of the food source $x_{i}$ by using (14) and evaluate its quality:

Select randomly $a \neq b \neq i$

$$
v_{i j}=\left\{\begin{array}{lr}
x_{a j}+\varphi_{i j}\left(x_{i j}-x_{b j}\right), & \text { if } R_{i j} \leq M R \\
x_{i j} & \text { otherwise }
\end{array}\right.
$$

Apply a greedy selection process between $v_{i}$ and $x_{i}$ and select the better one. If solution $x_{i}$ does not improve trial $l_{i}=$ trial $_{i}+1$, otherwise trial $_{i}=0$

\section{end for}

Calculate the probability values $p_{i}$ by (10) for the solutions using fitness values:

$$
p_{i}=\alpha \times \frac{f_{i t}}{\max \left(\text { fit }_{i}\right)}+\beta ; \quad \alpha+\beta=1
$$

$t=0, i=1$

\{--- Produce a new food source population for onlooker bee --- $\}$

repeat

if random $<p_{i}$ then

Produce a new $v_{i j}$ food source by (14) for the onlooker bee:

Select randomly $a \neq b \neq i$

$$
v_{i j}= \begin{cases}x_{a j}+\varphi_{i j}\left(x_{i j}-x_{b j}\right), & \text { if } R_{i j} \leq M R \\ x_{i j} & \text { otherwise }\end{cases}
$$

Apply a greedy selection process between $v_{i}$ and $x_{i}$ and select the better one. If solution $x_{i}$ does not improve trial $l_{i}=$ trial $_{i}+1$, otherwise trial $_{i}=0$

$t=t+1$

end if

until $(t=S N)$

if $\max \left(\right.$ trial $\left._{i}\right)>$ limit then

$$
\{--- \text { Determine scout bee --- }\}
$$

Replace $x_{i}$ with a new randomly produced solution by (11)

$$
x_{i j}=x_{j \text { min }}+\operatorname{rand}(0,1) *\left(x_{j \max }-x_{j \text { min }}\right)
$$

end if

Memorize the best solution achieved so far

cycle $=$ cycle +1

until (cycle = Maximum Cycle Number)

\section{SIMULATION RESULTS AND DISCUSSION}

In the study of experiment, MABC algorithm is tested over standard IEEE 30-bus power system with six generating units as shown in Fig. 1. The parameters of all thermal units are presented in Table 1, followed by $B$-loss coefficient [9, $11,18]$. The values of MABC algorithm for solving CEED problem in this paper are designated as follow: 


\title{
International Journal of Advanced Research in Electrical, Electronics and Instrumentation Engineering
}

\author{
(An ISO 3297: 2007 Certified Organization)
}

\section{Vol. 4, Issue 11, November 2015}

The number of colony size, $\mathrm{NP}=20$; the number of cycles for aging, maxCycle $=300$; the number of variables, $\mathrm{NV}=$ 6 ; and limit $=100$.

The proposed technique is applied for CEED problem with load demands 500 MW, 700 MW, and 900 MW, respectively and it is compared with FCGA and NSGA-II [25]. Minimum fuel cost solution for CEED problem with all load demands are considered respectively in Table 2, Table 3, and Table 4. Minimum $\mathrm{NO}_{\mathrm{x}}$ emission effect solution for CEED problem with all load demands are considered respectively in Table 5, Table 6, and Table 7 . The best compromise solution for CEED problem with all load demands are considered respectively in Table 8, Table 9, and Table 10.

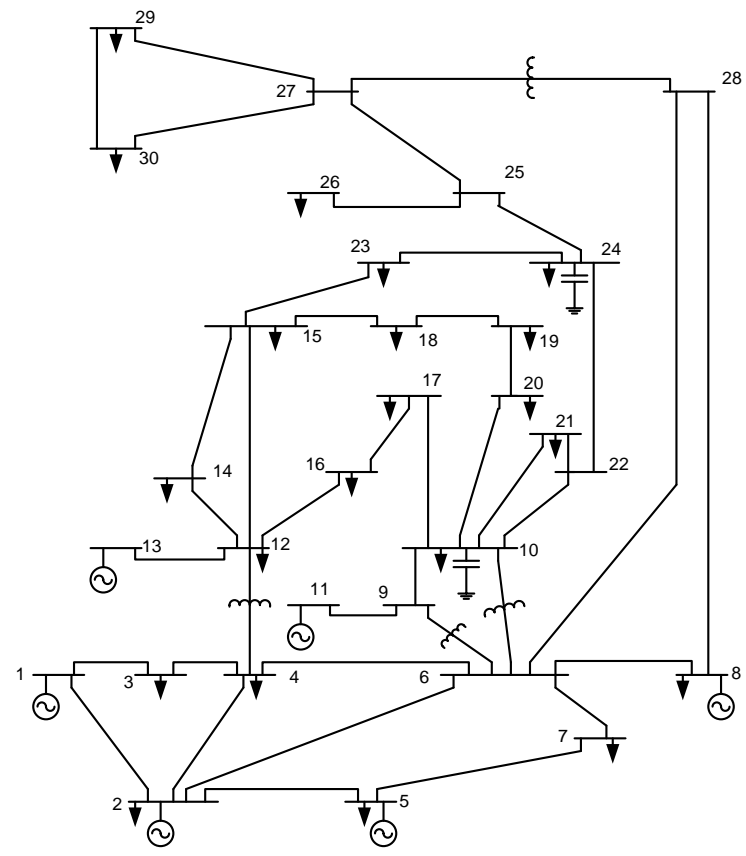

Fig. 1 Single-line diagram of IEEE 30-bus test system [18]

Table 1 Generator capacity limits, fuel cost and emission coefficients for IEEE 30-bus test system

\begin{tabular}{lllcccccc}
\hline Unit & $\begin{array}{l}P_{i}^{\text {min }} \\
(\mathrm{MW})\end{array}$ & $\begin{array}{c}P_{i}^{\text {max }} \\
(\mathrm{MW})\end{array}$ & $\begin{array}{c}\mathrm{a}_{\mathrm{i}} \\
\left(\$ / \mathrm{MW}^{2}\right)\end{array}$ & $\begin{array}{c}\mathrm{b}_{\mathrm{i}} \\
(\$ / \mathrm{MW})\end{array}$ & $\begin{array}{c}\mathrm{c}_{\mathrm{i}} \\
(\$)\end{array}$ & $\begin{array}{c}\alpha_{\mathrm{i}} \\
\left(\$ / \mathrm{MW}^{2}\right)\end{array}$ & \multicolumn{1}{c}{$\begin{array}{c}\beta_{\mathrm{i}} \\
(\$ / \mathrm{MW})\end{array}$} & $\begin{array}{c}\gamma_{\mathrm{i}} \\
(\$)\end{array}$ \\
\hline 1 & 10 & 125 & 0.15240 & 38.53973 & 756.79886 & 0.00419 & 0.32767 & 13.85932 \\
2 & 10 & 150 & 0.10587 & 46.15916 & 451.32513 & 0.00419 & 0.32767 & 13.85932 \\
3 & 35 & 225 & 0.02803 & 40.39655 & 1049.9977 & 0.00683 & -0.54551 & 40.26690 \\
4 & 35 & 210 & 0.03546 & 38.30553 & 1243.5311 & 0.00683 & -0.54551 & 40.26690 \\
5 & 130 & 325 & 0.02111 & 36.32782 & 1658.5596 & 0.00461 & -0.51116 & 42.89553 \\
6 & 125 & 315 & 0.01799 & 38.27041 & 1356.6592 & 0.00461 & -0.51116 & 42.89553 \\
\hline
\end{tabular}

$$
B_{i j}=\left[\begin{array}{rrrrrr}
0.002022 & -0.000286 & -0.000534 & -0.000565 & -0.000454 & -0.000103 \\
-0.000286 & 0.003243 & 0.000016 & -0.000307 & -0.000422 & -0.000147 \\
-0.000534 & 0.000016 & 0.002085 & 0.000831 & 0.000023 & -0.000270 \\
-0.000565 & -0.000307 & 0.000831 & 0.001129 & 0.000113 & -0.000295 \\
-0.000454 & -0.000422 & 0.000023 & 0.000113 & 0.000460 & -0.000153 \\
-0.000103 & -0.000147 & -0.000270 & -0.000295 & -0.000153 & 0.000898
\end{array}\right]
$$


International Journal of Advanced Research in Electrical, Electronics and Instrumentation Engineering

(An ISO 3297: 2007 Certified Organization)

Vol. 4, Issue 11, November 2015

Table 2 Best fuel cost for 6-generator system $\left(\mathrm{P}_{\mathrm{D}}=500 \mathrm{MW}\right)$

\begin{tabular}{lccc}
\hline Unit Output & FCGA & NSGA-II & MABC \\
\hline P1 (MW) & 49.47 & 50.836 & 52.1024 \\
P2 (MW) & 29.40 & 31.806 & 29.0471 \\
P3 (MW) & 35.31 & 35.12 & 40.0000 \\
P4 (MW) & 70.42 & 73.44 & 68.0901 \\
P5 (MW) & 199.03 & 191.988 & 191.4150 \\
P6 (MW) & 135.22 & 135.019 & 136.4637 \\
Fuel cost (\$/h) & 28150.80 & 28150.834 & 28086.9456 \\
Emission (kg/h) & 314.53 & 309.04 & 306.3324 \\
Power losses (MW) & 18.86 & 18.208 & 17.1183 \\
Total Capacity (MW) & 518.86 & 518.208 & 517.1183 \\
\hline
\end{tabular}

Table 3 Best fuel cost for 6-generator system $\left(P_{D}=700 \mathrm{MW}\right)$

\begin{tabular}{lccc}
\hline Unit Output & FCGA & NSGA-II & MABC \\
\hline P1 (MW) & 72.14 & 76.179 & 76.0897 \\
P2 (MW) & 50.02 & 51.81 & 49.0586 \\
P3 (MW) & 46.47 & 49.82 & 45.3525 \\
P4 (MW) & 99.33 & 103.407 & 102.7347 \\
P5 (MW) & 264.60 & 267.984 & 266.3914 \\
P6 (MW) & 203.58 & 184.734 & 191.3422 \\
Fuel cost (\$/h) & 38384.09 & 38370.746 & 38207.5910 \\
Emission (kg/h) & 543.48 & 534.924 & 532.6970 \\
Power losses (MW) & 36.15 & 33.934 & 30.9692 \\
Total Capacity (MW) & 736.14 & 733.934 & 730.9692 \\
\hline
\end{tabular}

Table 4 Best fuel cost for 6-generator system $\left(P_{D}=900 \mathrm{MW}\right)$

\begin{tabular}{lccc}
\hline Unit Output & FCGA & NSGA-II & MABC \\
\hline P1 (MW) & 101.11 & 102.963 & 103.4811 \\
P2 (MW) & 67.64 & 74.235 & 70.1005 \\
P3 (MW) & 50.39 & 66.003 & 60.6818 \\
P4 (MW) & 158.80 & 140.316 & 139.5618 \\
P5 (MW) & 324.08 & 324.888 & 325.0000 \\
P6 (MW) & 256.56 & 248.416 & 251.7912 \\
Fuel cost (\$/h) & 49655.40 & 49620.824 & 49297.9331 \\
Emission (kg/h) & 877.61 & 849.326 & 845.6922 \\
Power losses (MW) & 58.58 & 56.822 & 50.6162 \\
Total Capacity (MW) & 958.57 & 956.822 & 950.662 \\
\hline
\end{tabular}

Table 5 Best emission effects for 6-generator system $\left(\mathrm{P}_{\mathrm{D}}=500 \mathrm{MW}\right)$

\begin{tabular}{lccc}
\hline Unit Output & FCGA & NSGA-II & MABC \\
\hline P1 (MW) & 81.08 & 56.931 & 58.0644 \\
P2 (MW) & 13.93 & 41.542 & 43.7211 \\
P3 (MW) & 66.37 & 73.896 & 75.7252 \\
P4 (MW) & 85.58 & 84.931 & 83.9750 \\
P5 (MW) & 141.70 & 136.502 & 133.4545 \\
P6 (MW) & 135.93 & 131.328 & 128.7771 \\
Fuel cost (\$/h) & 28756.71 & 28641.078 & 28626.5205 \\
Emission $(\mathrm{kg} / \mathrm{h})$ & 286.59 & 275.544 & 274.2547 \\
Power losses $(\mathrm{MW})$ & 24.61 & 25.129 & 23.7172 \\
Total Capacity (MW) & 524.61 & 525.129 & 523.7172 \\
\hline
\end{tabular}




\section{International Journal of Advanced Research in Electrical, Electronics and Instrumentation Engineering}

(An ISO 3297: 2007 Certified Organization)

\section{Vol. 4, Issue 11, November 2015}

Table 6 Best emission effects for 6-generator system $\left(P_{D}=700 \mathrm{MW}\right)$

\begin{tabular}{lccc}
\hline Unit Output & FCGA & NSGA-II & MABC \\
\hline P1 (MW) & 120.16 & 103.078 & 105.3292 \\
P2 (MW) & 21.36 & 73.505 & 76.4086 \\
P3 (MW) & 62.09 & 91.556 & 92.9206 \\
P4 (MW) & 128.05 & 110.787 & 109.8345 \\
P5 (MW) & 209.65 & 187.869 & 183.1928 \\
P6 (MW) & 201.12 & 174.289 & 170.0132 \\
Fuel cost (\$/h) & 39455.00 & 39473.433 & 39433.4776 \\
Emission (kg/h) & 516.55 & 467.388 & 462.7169 \\
Power losses (MW) & 42.44 & 41.083 & 37.6990 \\
Total Capacity (MW) & 742.44 & 741.083 & 737.6990 \\
\hline
\end{tabular}

Table 7 Best emission effects for 6-generator system $\left(P_{D}=900 \mathrm{MW}\right)$

\begin{tabular}{lccc}
\hline Unit Output & FCGA & NSGA-II & MABC \\
\hline P1 (MW) & 133.31 & 124.998 & 124.9894 \\
P2 (MW) & 110.00 & 109.893 & 88.3224 \\
P3 (MW) & 100.38 & 111.081 & 123.9540 \\
P4 (MW) & 119.27 & 141.961 & 134.8330 \\
P5 (MW) & 250.79 & 254.36 & 274.6471 \\
P6 (MW) & 251.25 & 226.578 & 215.4800 \\
Fuel cost (\$/h) & 53299.64 & 51254.195 & 50517.6331 \\
Emission (kg/h) & 785.64 & 760.052 & 751.2743 \\
Power losses (MW) & 65.00 & 68.87 & 62.2260 \\
Total Capacity (MW) & 965.00 & 968.87 & 962.2260 \\
\hline
\end{tabular}

Table 8 Best compromise solution for 6-generator system $\left(\mathrm{P}_{\mathrm{D}}=500 \mathrm{MW}\right)$

\begin{tabular}{lccc}
\hline Unit Output & FCGA & NSGA-II & MABC \\
\hline P1 (MW) & 65.23 & 54.048 & 54.7203 \\
P2 (MW) & 24.29 & 34.250 & 32.5975 \\
P3 (MW) & 40.44 & 54.497 & 49.2279 \\
P4 (MW) & 74.22 & 80.413 & 77.7303 \\
P5 (MW) & 187.75 & 161.874 & 166.3428 \\
P6 (MW) & 125.48 & 135.426 & 137.2141 \\
Fuel cost (\$/h) & 28231.06 & 28291.119 & 28164.7430 \\
Emission (kg/h) & 304.90 & 284.362 & 282.4029 \\
Power losses (MW) & 17.41 & 20.508 & 17.1428 \\
Total Capacity (MW) & 517.41 & 520.508 & 517.1428 \\
\hline
\end{tabular}

Table 9 Best compromise solution for 6-generator system $\left(\mathrm{P}_{\mathrm{D}}=700 \mathrm{MW}\right)$

\begin{tabular}{lccc}
\hline Unit Output & FCGA & NSGA-II & MABC \\
\hline P1 (MW) & 80.16 & 86.286 & 84.1509 \\
P2 (MW) & 53.71 & 60.288 & 55.6554 \\
P3 (MW) & 40.93 & 73.064 & 66.0050 \\
P4 (MW) & 116.23 & 109.036 & 107.2668 \\
P5 (MW) & 251.20 & 223.448 & 230.9310 \\
P6 (MW) & 190.62 & 184.111 & 187.6477 \\
Fuel cost (\$/h) & 38408.82 & 38671.813 & 38371.8924 \\
Emission (kg/h) & 527.46 & 484.931 & 476.5373 \\
Power losses (MW) & 32.85 & 36.234 & 31.6568 \\
Total Capacity (MW) & 732.85 & 736.234 & 731.6568 \\
\hline
\end{tabular}




\section{International Journal of Advanced Research in Electrical, Electronics and Instrumentation Engineering}

(An ISO 3297: 2007 Certified Organization)

\section{Vol. 4, Issue 11, November 2015}

Table 10 Best compromise solution for 6-generator system $\left(\mathrm{P}_{\mathrm{D}}=900 \mathrm{MW}\right)$

\begin{tabular}{lccc}
\hline Unit Output & FCGA & NSGA-II & MABC \\
\hline P1 (MW) & 111.40 & 120.052 & 115.2769 \\
P2 (MW) & 69.33 & 85.203 & 78.8093 \\
P3 (MW) & 59.43 & 89.565 & 81.3885 \\
P4 (MW) & 143.26 & 140.278 & 137.3458 \\
P5 (MW) & 319.40 & 288.614 & 298.6779 \\
P6 (MW) & 252.11 & 233.687 & 238.1785 \\
Fuel cost (\$/h) & 49674.28 & 50126.059 & 49553.8355 \\
Emission (kg/h) & 850.29 & 784.696 & 772.4565 \\
Power losses (MW) & 54.92 & 57.405 & 49.6769 \\
Total Capacity (MW) & 954.92 & 957.405 & 949.6769 \\
\hline
\end{tabular}

Summary of the results in Table 2 to Table 10 for the best completion of MABC method compared with NSGA-II in order to reduce fuel costs, emissions, and power losses are shown in Table 11. After comparing the simulation results with the others method, it is obviously seen that proposed MABC algorithm give more powerful results than other algorithms.

Table 11 Summary of MABC VS NSGA-II for 6-generator system

\begin{tabular}{lrrr}
\hline & \multicolumn{3}{c}{ Load (MW) } \\
& \multicolumn{5}{c}{$\mathbf{5 0 0}$} & \multicolumn{1}{c}{$\mathbf{7 0 0}$} & \multicolumn{1}{c}{$\mathbf{9 0 0}$} \\
\hline Best fuel cost & & & \\
Fuel cost $(\$ / \mathrm{h})$ & 63.8884 & 163.1550 & 322.8909 \\
Emission $(\mathrm{kg} / \mathrm{h})$ & 2.7076 & 2.2270 & 3.6338 \\
Power losses $(\mathrm{MW})$ & 1.0897 & 2.9648 & 6.2058 \\
Best emission & & & \\
Fuel cost $(\$ / \mathrm{h})$ & 14.5575 & 39.9554 & 736.5619 \\
Emission $(\mathrm{kg} / \mathrm{h})$ & 1.2893 & 4.6711 & 8.7777 \\
Power losses $(\mathrm{MW})$ & 1.4118 & 3.3840 & 6.6440 \\
Best compromise & & & \\
Fuel cost $(\$ / \mathrm{h})$ & 126.3760 & 299.9206 & 572.2235 \\
Emission $(\mathrm{kg} / \mathrm{h})$ & 1.9591 & 8.3937 & 12.2395 \\
Power losses $(\mathrm{MW})$ & 3.3652 & 4.5772 & 7.7281 \\
\hline
\end{tabular}

\section{CONCLUSION}

This paper has presented a new optimization algorithm to solve the combined economic emission dispatch problem considering linear equality and inequality constraints and also considering transmission losses. Economic and emission dispatch is a multi-objective problem. But the present approach makes use of only one objective function and depending upon the problem such as economic, emission or combined economic and emission dispatch, only the coefficients of the objective function has to be changed. The feasibility of the proposed method for solving CEED problems is demonstrated using IEEE 30-bus test system with six generating units. The comparison of the results with other methods reported in the literature shows the superiority of the proposed method and its potential for solving CEED problems in a power system. From the results obtained, it can be concluded that the MABC algorithm is a promising technique for solving complex optimization problems in power system operation.

\section{REFERENCES}

[1] A.J Wood, B.F. Wollenberg. Power Generation Operation and Control. John Wiley and Sons, New York, 1984.

[2] Hadi Saadat. Power System Analysis. Tata McGraw Hill Publishing Company, New Delhi, 2002.

[3] S.Y. Lim, M. Montakhab, H. Nouri, "Economic Dispatch of Power System using Particle Swarm Optimization with Constriction Factor", Int. J. Innov. Energy Syst. Power, vol. 4, no. 2, pp. 29-34, 2009.

[4] Z. L. Gaing, "Particle Swarm Optimization to Solving the Economic Dispatch Considering the Generator Constraints", IEEE Trans. Power Syst., vol. 18, no. 3, pp. 1187-1195, 2003

[5] D. C. Walters, G. B. Sheble, "Genetic Algorithm Solution of Economic Dispatch with Valve Point Loading", IEEE Trans. Power Syst., vol. 8, no. 3, pp. 1325-1332, 1993 


\section{International Journal of Advanced Research in Electrical, Electronics and Instrumentation Engineering}

\section{(An ISO 3297: 2007 Certified Organization)}

\section{Vol. 4, Issue 11, November 2015}

[6] T. Ratniyomchai, A. Oonsivilai, P. Pao-La-Or, T. Kulworawanichpong, "Particle Swarm Optimization for Solving Combined Economic and Emission Dispatch Problems", 5th IASME/WSEAS Int. Conf. Energy Environ, pp. 211-216, 2010.

[7] C. Palanichamy, N. S. Babu, ”Analytical Solution for Combined Economic and Emissions Dispatch", Elect. Power Systs. Res., vol. 78, pp. 11291137, 2008.

[8] N. Cetinkaya, "Optimization Algorithm for Combined Economic and Emission Dispatch with Security Constraints", Int. Conf. Comp. Sci. Appl. ICCSA, pp. 150-153, 2009.

[9] R. Balamurugan, S. Subramanian, ”A Simplified Recursive Approach to Combined Economic Emission Dispatch", Elec. Power Comp. Syst., vol. 36, no. 1,pp. 17-27, 2008

[10] L. Abdelhakem Koridak, M. Rahli, M. Younes, "Hybrid Optimization of the Emission and Economic Dispatch by the Genetic Algorithm", Leonardo Journal of Sciences, Issue 14, pp. 193-203, 2008.

[11] U. Güvenç, "Combined Economic Emission Dispatch Solution using Genetic Algorithm Based on Similarity Crossover", Sci. Res. Essay, vol. 5, no. 17, pp. 2451-2456, 2010.

[12] Simon Dinu, Ioan Odagescu, Maria Moise, "Environmental Economic Dispatch Optimization using a Modified Genetic Algorithm", International Journal of Computer Applications, vol. 20, no. 2, pp. 7-14, 2011.

[13] J. Sasikala, M. Ramaswamy, "Optimal $\lambda$ Based Economic Emission Dispatch using Simulated Annealing”, Int. J. Comp. Appl., vol. 1, no. 10, pp. 5563, 2010.

[14] P. K. Roy, S. P. Ghoshal, S. S. Thakur, "Combined Economic and Emission Dispatch Problems using Biogeography-Based Optimization", Electr. Eng., vol. 92, no. 4-5, pp. 173-184, 2010 .

[15] Y. M. Chen, W. S. Wang, "Particle Swarm Approach to Solve Environmental/Economic Dispatch Problem", International Journal of Industrial Engineering Computations, vol. 1, pp. 157-172, 2010.

[16] Anurag Gupta, K. K. Swarnkar, K. Wadhwani, "Combined Economic Emission Dispatch Problem using Particle Swarm Optimization”, International Journal of Computer Applications, vol. 49, no. 6, pp. 1-6, 2012.

[17] S. Hemamalini, S. P. Simon, ’Economic/Emission Load Dispatch using Artificial Bee Colony Algorithm', Int. Conf. Cont., Comm. Power Eng., pp. $338-343,2010$

[18] Y. Sonmez, "Multi-Objective Environmental/Economic Dispatch Solution with Penalty Factor using Artificial Bee Colony Algorithm", Sci. Res. Essay, vol. 6, no. 13, pp. 2824-2831, 2011.

[19] D. Karaboga, B. Basturk, ”On the Performance of Artificial Bee Colony (ABC) Algorithm”, Applied Soft Computing, vol. 8, no. 1, pp. 687- 697, 2008.

[20] D. Karaboga, B. Akay, "Artificial Bee Colony (ABC), Harmony Search and Bees Algorithms on Numerical Optimization", Proceedings of IPROMS 2009 Conference, pp. 1-6, 2009

[21] B. Akay, D. Karaboga, ”A Modified Artificial Bee Colony Algorithm for Real-Parameter Optimization”, Information Sciences, vol. 192, pp. 120142,2012

[22] X. T. Li, X. W. Zhao, J. N. Wang, M. H. Yin, "Improved Artificial Bee Colony for Design of a Reconfigurable Antenna Array with Discrete Phase Shifters", Progress in Electromagnetics Research C, vol. 25, pp. 193-208, 2012.

[23] R. Storn, K. Price, "Differential Evolution a Simple and Efficient Heuristic for Global Optimization Over Continuous Spaces", Journal of Global Optimization, vol. 11, no. 4, pp. 341-359, 1997.

[24] K. Price, R. Storn, J. A. Lampinen. Differential Evolution: A Practical Approach to Global Optimization. Springer, Berlin, Heidelberg, 2005.

[25] HCS Rughooputh, RTFA King, "Environmental/Economic Dispatch of Thermal Units using an Elitist Multi-Objective Evolutionary Algorithm", IEEE Int. Conf. Ind. Tech., pp. 48-53, 2003.

\section{BIOGRAPHY}

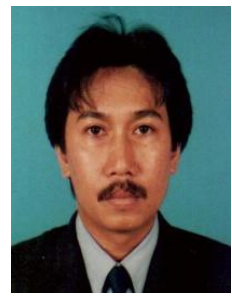

Hardiansyah was born on February 27, 1967 in Mempawah, Indonesia. He received the B.S. degree in Electrical Engineering from the University of Tanjungpura in 1992 and the M.S. degree in Electrical Engineering from Bandung Institute of Technology (ITB), Indonesia in 1996. Dr. Eng, degree from Nagaoka University of Technology in 2004. Since 1992, he has been with Department of Electrical Engineering, University of Tanjungpura, Pontianak, Indonesia. Currently, he is a senior lecturer in Electrical Engineering. His current research interests include power system operation and control, robust control, and soft computing techniques in power system.

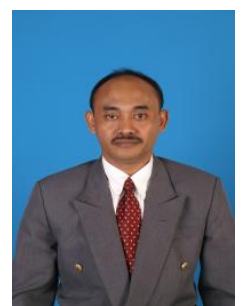

Rusman was born on September 22, 1967 in Singkawang, Indonesia. He received the B.S. degree in Electrical Engineering from the University of Tanjungpura in 1992 and the M.S. degree in Electrical Engineering from University of Tanjungpura, Indonesia in 2012. Since 1998, he has been with Department of Electrical Engineering, State Polytechnic of Pontianak, Indonesia. Currently, he is a senior lecturer in Electrical Engineering. His current research interests include power system operation and control, power system protection, and soft computing techniques in power system. 